J. Biosoc. Sci., (2016) 48, S1-S15 C Cambridge University Press, 2016. This is an Open Access article, distributed under the terms of the Creative Commons Attribution licence (http:// creativecommons.org/licenses/by/4.0/), which permits unrestricted re-use, distribution, and reproduction in any medium, provided the original work is properly cited.

doi:10.1017/S0021932016000274

\title{
SPECIAL ISSUE ON BIOSOCIAL APPROACHES TO THE CONTROL OF NEGLECTED TROPICAL DISEASES
}

\section{NEGLECTED TROPICAL DISEASES IN BIOSOCIAL PERSPECTIVE}

\author{
MELISSA PARKER* ${ }^{1}$, KATJA POLMAN $\dagger$ AND TIM ALLEN $\ddagger$ \\ * Department of Global Health and Development, London School of Hygiene and \\ Tropical Medicine, UK, †Institute of Tropical Medicine, Antwerp, Belgium and \\ $\ddagger$ Department of International Development, London School of Economics, UK
}

\begin{abstract}
Summary. The term 'neglected tropical diseases' (NTDs) points to the need for a biosocial perspective. Although 'diseases' are widely understood as biological phenomena, 'neglect' is inherently social. Social priorities, social relations and social behaviour profoundly influence the design, implementation and evaluation of control programmes. Yet, these dimensions of neglect are, themselves, neglected. Instead, emphasis is being placed on preventive chemotherapy - a technical, context-free approach which relies almost entirely on the mass distribution of drugs, at regular intervals, to populations living in endemic areas. This article reflects on the processes which have enabled an NTD 'brand' identity to emerge, and it comments on a disquieting disengagement with some of the more critical insights about the consequences of mass drug administration. Building on the work of biosocial scholars studying other aspects of health and disease, a more adequate, evidence-based approach is delineated. Developing such an approach is an iterative process, requiring on-going engagement with both biological and social insights as they emerge. Considerable theoretical, methodological and political challenges lie ahead, but it is essential they are overcome, if the sustainable control of NTDs is to become a reality.
\end{abstract}

\section{Introduction}

The term 'neglected tropical diseases' (NTDs) points to the need for a biosocial perspective. Although 'diseases' are typically understood as biological phenomena, 'neglect' arises from social priorities, social relations and social behaviour. Yet, more often than not, the dual aspect of NTDs is set aside in the design, implementation and

${ }^{1}$ Corresponding author. Email: melissa.parker@1shtm.ac.uk 
evaluation of control programmes. Instead, emphasis is placed on preventive chemotherapy, an approach which relies heavily on the mass distribution of drugs, at regular intervals and free of charge, to populations living in endemic areas. Framed as technical solutions, NTD control programmes are rolled out across countries and continents, irrespective of the specific contexts in which they are delivered. Writing from diverse viewpoints, and citing numerous examples, the authors contributing to this special issue make the case for a re-orientation in both research and policy.

\section{Challenges facing the NTD 'brand'}

Ideas underpinning contemporary approaches to the control of NTDs relate to the work of the Great Neglected Diseases (GND) network of the 1970s and 1980s (Hotez et al., 2008; Regnier, 2012; Keating, 2014). During the years before and after the turn of the new Millennium, there was a concerted effort to link the philanthropic aspects of the GND network, which focused on particular tropical infections (such as schistosomiasis), with an approach that replicated key aspects of UNICEF's selective primary health care strategies of the 1980s (Allotey et al., 2010; Regnier, 2012). Emphasis was placed on the reported health and economic benefits that had accrued in the past from the treatment for parasitic worms in affluent countries (Bleakley, 2002; Miguel \& Kremer, 2004), and an argument was made that there were effective medicines that might be used on a large scale. As one of the main advocates, Lorenzo Savioli, put it: there was a 'paradigm shift' entailing: 'a strategic rethinking and move away from a "theoretical", structural classification based on disease biology towards a "practical" one based on the available tools...' (Savioli et al., 2011, p. 481).

Together with other like-minded figures, Savioli promoted 'NTDs' as a 'brand identity', and campaigned to establish mass drug administration as an appropriate response (Savioli et al., 2011; Molyneux, 2012). Building on discussions at a meeting convened by the World Health Organization in 2003, a 'Department of Control of Neglected Tropical Diseases' was set up in Geneva under his leadership. Then, in 2005, a Global Network for NTDs was launched to raise the profile of this group of diseases, and encourage a shift away from the emphasis on HIV/AIDS, malaria and tuberculosis (Allen \& Parker, 2011; Nordrum, 2015). The overall intention was to raise awareness, and secure funds, political will and supplies of medications, with a view to systematically controlling the NTDs. The strategy was explicitly linked to the Millennium Development Goals, which had mentioned the need to combat 'other diseases' alongside HIV/AIDS and malaria.

Targets were promoted for the mass treatment of populations living in endemic areas, and far-reaching claims were made about the possible benefits. For example, influential articles by three leading advocates, Molyneux, Hotez and Fenwick, argued that controlling the NTDs has the potential to 'make poverty history' (Molyneux et al., 2005, p. 106) and to 'rescue the bottom billion from poverty' (Hotez et al., 2009, p. 1570). By the end of the decade, the WHO had released its first global report on NTDs (WHO, 2010), and the Director General could proclaim that: 'WHO leadership [has] brought the neglected tropical diseases from obscurity into the limelight. These Cinderella diseases, long ignored and underappreciated, are a rags-to-riches story' (Chan, 2012). An indication of the enthusiasm for the approach at that time is reflected in Savioli's published remarks at an Institute of Medicine workshop. He acknowledged that there were regional specificities, but suggested that this complicated global efforts to 
reduce the burden of NTDs. He then went on to quote a famous Formula One racing driver: 'If you think you have everything under control, you are not going fast enough ... that's the way we need to deal with the issue sometimes' (Choffnes \& Relman, 2011, p. 56).

Seventeen 'core' NTDs have been foregrounded by the WHO (WHO, 2010, 2013); and it has been argued that seven of them can be controlled or eliminated by utilizing preventive chemotherapy. This approach has been defined as 'the large-scale delivery of safe, single-administration, quality-assured medicines, either alone or in combination, at regular intervals, to entire population groups' (WHO 2015a, p. 50). It aims to reduce infection and prevent the development of severe morbidity. The diseases being targeted in this way are: lymphatic filariasis, onchocerciasis, schistosomiasis, soil-transmitted helminthiases (notably ascariasis, trichuriasis and hookworm) and trachoma. The WHO's willingness to promote preventive chemotherapy would not have occurred without the widespread availability of four drugs (albendazole, ivermectin, praziquantel and azithromycin) to treat these diseases. Pharmaceutical companies, such as Merck and GlaxoSmithKline, have donated hundreds of millions of these drugs. This has helped trigger political momentum, and thus enabled the allocation of substantial resources and finance. By December 2012, an estimated US\$3.2 billion had been donated from diverse sources (Policy Cures, 2012), including bilateral agencies such as USAID and the UK Department for International Development, UN agencies, the World Bank, philanthropic institutions such as the Bill and Melinda Gates Foundation and international NGOs such as the End Fund. Even those who have been at the centre of promoting mass drug administration recognize that calling the diseases 'neglected' has now become a misnomer. As Fenwick, a key figure in the promotion of mass drug administration, recently said: 'If 700 million people are receiving treatment free of charge, how neglected are they? However, having sold the brand, we don't want to destroy it quite yet' (quoted in Nordrum, 2015).

There is no doubt that establishing the NTD 'brand' has been a remarkable achievement. There is widespread agreement that it is reasonable and appropriate to focus on debilitating infections that afflict impoverished people. It is also irrefutable that huge numbers of tablets have become available to populations that, in the not so distant past, were largely ignored. However, there are increasing concerns with relying so heavily on the mass distribution of drugs, and these have been expressed by biological and social scientists alike.

First, while the prevalence and intensity of infection usually declines following mass treatment for NTDs, they often return to their former levels in the absence of wider socioeconomic changes (e.g. Saeed et al., 2006; Nikolay et al., 2015; Amin \& Abu Baker, 2016). Given this, an argument could be made for making an indefinite commitment to mass drug administration. However, this raises a second concern: the possibility of declining effectiveness and/or resistance occurring to front-line drugs. The point has been elaborated, for example, with respect to praziquantel (Gryseels et al., 2006; Mahmoud \& Zerhouni, 2009; Gray et al., 2010), albendazole (Geerts \& Gryseels, 2000; Waghorn, 2006; Humphries et al., 2012) and the combined use of ivermectin with albendazole (Simonson et al., 2010).

A third issue concerns the fact that drug coverage levels are variable, and they often fall below the levels required to systematically control infection. Explanations for low 
drug coverage vary not only between the diseases being treated, but also within and between countries for any one disease, reflecting the fact that historical, political, economic and social issues powerfully influence local responses to mass drug administration (e.g. Parker et al., 2008, 2012; Hastings, 2013, 2016). The drugs themselves can also have a direct impact on coverage levels, simply because some of them are easier to swallow than others. In many instances it has been shown that irrespective of the reported coverage levels, large numbers of people being targeted either refuse to swallow them or they are not offered them in the first place (e.g. Ranganath, 2010; Parker \& Allen, 2011, 2013; Roy et al., 2013; Muhumuza et al., 2013, 2015; Kisoka et al., 2014, 2016; Tuhebwe et al., 2015).

These points relate to a fourth broad area of concern: the role of drug distributors in mass treatment programmes. In countries where great reliance is placed on unpaid (and usually poorly trained) volunteers to distribute drugs, it has been shown that they are rarely able to provide convincing explanations for the need to take these drugs, particularly when someone has no signs or symptoms of infection or the likelihood of re-infection is perceived to be high (e.g. Parker \& Allen, 2011; Samsky, 2012; Kisoka et al., 2016).

A fifth challenge evident in the literature is the fact that current approaches to implementing mass drug administration programmes can have adverse effects on already fragile and over-stretched health systems (Coulibaly et al., 2008; Cavalli et al., 2010; Marchal et al., 2011; Meheus et al., 2012). Along these lines, it has also been argued that when donors require parallel drug distribution mechanisms to be established, the 'competing' programmes can create confusion at a local level. Indeed, they can end up deflecting attention away from other priorities and make sustainable, broad-based primary care more difficult to achieve (Yamey, 2009; Kabatereine et al., 2010). For some analysts, there has been too much focus on the vertical delivery of tablets, and the lack of attention to the social and political context has marked a counter-productive resurgence of simplistic 'magic bullet' medicine (Allotey et al., 2010).

\section{A biosocial way forward?}

A diverse group of biological and social scientists have contributed to the literature cited above. Taken together, their work comprises a serious critique of current endeavours to rely on mass drug administration to control NTDs. In July 2013, some of these scholars attended an international workshop at the Royal Anthropological Institute and Brunel University, London. It was organized under the auspices of the Biosocial Society. The idea was to make a concerted effort to move beyond the exaggerated rhetoric surrounding strategies to control NTDs, as well as the unhelpful polarities between the biological and social sciences; and to explore the possibility of developing integrated, biosocial approaches to the control of NTDs. Most of the articles published in this special issue were originally presented at the workshop. The discussion was lively, and occasionally fraught. Starting points were very different. Nevertheless, a consensus emerged that developing biosocial approaches to the control of NTDs was a useful way forward.

Such approaches build directly on the work of Goodman and Leatherman (1998), Kleinman et al. (2008), Leatherman and Goodman (2011), Farmer et al. (2013) and Singer (2015), all of whom have argued the case for developing critically engaged, 
biosocial perspectives on health and disease. Their work does not focus on NTDs, but it is useful nonetheless. Goodman and Leatherman's edited collection Building a New Biocultural Synthesis, for example, usefully identifies some of the epistemological challenges; and emphasizes the need for researchers to reflect on the way in which historical, political, social and economic relations shape power relations and the impact this can have on 'local biologies' (Goodman \& Leatherman, 1998, p. 15). 'Local biologies' is a term associated with the work of Margaret Lock (Lock, 1993, 2001), who has challenged the notion of homogeneous and universal biological knowledge, and has argued that understandings of the body, and therefore of diseases, ceaselessly interact with local environments, and are indistinct from other aspects of culture.

Dressler (2003) and Dufour (2006), having acknowledged the enormous contribution of this earlier work, go on to ask: what's cultural about biocultural research? Dufour suggests that much too much emphasis has been given to the 'biological' rather than the 'cultural' dimensions, while Dressler suggests that a rather descriptive and simplistic approach has been taken to the study of culture; and that it is important to develop a more serious theoretical engagement with the concept of culture for truly biocultural research to occur. He illustrates the latter point with reference to research exploring the inter-relationships between psychological stress, economic inequality and cultural processes.

Singer and Clare (2003), Kleinman et al. (1997, 2008), Sommerfeld (2003), Farmer et al. (2013) and Alley and Sommerfeld (2014) all emphasize the multi-disciplinary nature of biosocial research. They rightly point out that it is a collaborative venture which necessarily involves drawing upon insights from a diverse range of disciplines in the biological and social sciences. For some of these scholars, social suffering and structural violence are central concepts in biosocial approaches to disease and suffering, with the term 'social suffering' being used to highlight 'what political, economic and institutional power does to people and, reciprocally, how these forms of power themselves influence responses to social problems' (Kleinman et al., 1997, p. ix). Thus, a biosocial approach necessarily focuses on the inter-connections between biological and social aspects of life - and the multiple ways in which political, social, economic and historical issues at local, national and international levels influence and frame these relationships. Crucially, and this is the really difficult bit, it involves trying to do so on equal terms, or maybe, as Ingold and Palsson (2013) propose, to reject the distinction altogether, and attempt a unified approach to understanding the biological and social dimensions of human life.

Against this backdrop, it is helpful to ask: what constitutes a biosocial approach to the control of NTDs? Can it be achieved? Ideally, a biosocial approach involves drawing upon insights emerging from zoology, parasitology, ecology, epidemiology, clinical medicine and pharmacology; whilst simultaneously taking seriously, and giving equal weight to, insights emerging from anthropology, history, demography, economics and political science. It necessarily involves undertaking research with multiple methods, and investing time in thinking through how to put together insights from different disciplines in order to develop a more holistic understanding of: the impact of NTDs on overall health and well-being; the effects of current control and elimination strategies on the overall health of populations; the way in which global health governance and international finance shape national NTD programmes; the impact of these changes 
on local biologies; as well as an exploration of how global policies are understood at village, district and national levels. Developing such an approach is an iterative process, requiring on-going engagement with both biological and social insights as they emerge.

\section{Disciplinary tramlines and the status of evidence}

Considerable challenges lie ahead. In the world of NTDs, and global health more generally, it would be fair to say that it is rare indeed for an epidemiologist, parasitologist or public health specialist to work on an equal footing with an anthropologist, historian or political scientist. It is much more common for scholars to work either in parallel tramlines or for social scientists to be employed (often in fairly junior positions) in schools of public health as 'handmaidens of biomedicine', undertaking 'qualitative' social research (Allen \& Parker, 2012a). 'Qualitative' research typically elaborates a 'factorial model of disease' with complex social and cultural processes being conceptualized as discrete, measurable 'factors', acting as 'barriers' to the effective implementation of global health interventions (Parker \& Harper, 2006). Such work quickly becomes divorced from theoretical engagements in the social sciences and ends up lacking critical rigour, thereby leaving normative and simplistic ways of seeing unchallenged and reinforcing unhelpful assumptions about targeted populations.

There are multiple reasons for the enduring nature of this state of affairs, including the fact that critically engaged research undertaken by anthropologists and other social scientists often reveals the mistaken assumptions embedded in global health interventions as well as the unique ways in which interventions are shaped by the particular political, historical, social and economic contexts in which they are delivered. It can be difficult to revise interventions in the light of this kind of research, not least because adjustments typically require spending more money, rather than less, and in the eyes of donors, this makes the interventions less cost-effective and appealing.

Equally challenging is the fact that it is not always clear how to value different kinds of evidence. If a randomized control trial monitoring the effects of annual treatment on microfilarial loads at a sentinel surveillance site suggests that mass drug administration is effective at reducing the transmission of lymphatic filariasis, and ethnographic and survey research in neighbouring districts suggests that drug coverage is low, is it appropriate to reify one set of findings over another? Similarly, if a cohort study documenting changing patterns of infection among children suggests that annual treatment for schistosomiasis prevents severe morbidity, but social research undertaken in the same area suggests that migration prevents the majority of children from attending school on a regular basis, how should these different kinds of data be combined to assess the merits of a programme? If ethnographic research shows how social, economic and political issues influence the uptake of drugs at a local level - so much so, that in some places the same programme may have entirely different impacts within and between districts and regions - what are Ministries of Health, the World Health Organization and donors such as the Bill and Melinda Gates Foundation meant to do with such information? Should there be an anthropologist in every village monitoring the situation or is there another solution? What form should it take?

Engaging with biosocial issues raises a variety of other questions relevant to global health interventions more broadly. If, for example, conceptions of 'the social' among 
biomedical scientists are perceived by more critically inclined social scientists as being too simple, how should we proceed with more complex, nuanced understandings of what constitutes social life? It is fairly straightforward to show that external notions of a community living in social harmony often bear little relationship to local realities; and that projecting social harmony onto village life is unhelpful if global health programmes are to run effectively at a local level. However, it is far from clear what to do with ethnographic data revealing the complexity of social life in village settings. This is a particularly important point with respect to mass drug administration. For example, as indicated previously, many NTD programmes rely on unpaid, poorly trained volunteers to distribute drugs for the benefit of their 'community'. Such programmes assume that they will be willing to spend considerable amounts of time distributing drugs to everyone in their village, disregarding social and political divisions and overcoming economic constraints. The reality is rather different: gender, kin, religious, political, occupational and economic issues all influence the distribution of drugs within villages; and it is not unusual for the most marginal and vulnerable populations to be the least likely to be offered treatment (Boelaert et al., 2009; Parker et al., 2012; Parker \& Allen, 2013). Addressing these issues can feel insurmountable in a context when there is so much emphasis on scaling-up and increasing the number of people to be targeted, rather than reflecting on existing strategies to see whether a more diverse, multi-pronged (and probably more expensive) approach might work more effectively in practice.

This raises a further problem: the nature of evidence and the politics of (expert) knowledge. It is sometimes assumed that research, whether grounded in the social or biological sciences, will gradually enable the appropriate refinement of policies in the light of key findings. Such assumptions are mistaken. The relationship between evidence, policy and practice is neither simple nor causal (see Mosse, 2004, 2005 and 2013 for a useful discussion of these complexities in other fields of international development). There is often a clear hierarchy of evidence, with randomized control trials typically being presented as the epitome of high-quality research, and background information and expert opinion being presented as the lowest form of information. Insights emerging from historical or ethnographic research sometimes do not even feature in this pyramidal evidence hierarchy (Adams, 2013).

With respect to NTDs, the situation is additionally complicated by the fact that the broader political context in which mass drug administration has emerged as the primary strategy for controlling these diseases has not only influenced the design of mass drug administration programmes, but also the type of monitoring and evaluation undertaken once the programmes have been rolled out. For example, 'knowledge, attitudes and practice' surveys (which are relatively cheap and superficial) are often funded at the expense of long-term ethnographic research. In other words, the political economy of research has profoundly influenced the kind of evidence that is produced (and not produced); the kind of debate that has subsequently occurred (and not occurred); and the way in which particular kinds of evidence have been used in preference to other kinds of evidence. The end result has been a lack of triangulated research assessing the consequences of mass drug administration. There is an acute need for independent, rigorous assessments examining locally specific effects, and subjecting reported results to appropriate critical scrutiny (Allen \& Parker, 2012b; Parker \& Allen, 2014). 
Interestingly, Chris Whitty, acting in his capacity as the Director of Research and Chief Scientific Adviser at the UK's Department for International Development, implicitly acknowledged this point in a talk to members of parliament in London in December 2012. He highlighted the dangers of foregrounding certain kinds of evidence at the expense of other kinds of evidence, and the hazards of exaggerating the results of treatment programmes. In particular, he referred to data on the control of leprosy which suggested considerably greater reductions in prevalence than was actually the case. The result was that donors reduced their funding for leprosy control in the mistaken belief that the disease is no longer a serious problem. He went on to note that the targets being emphasized to secure support for control programmes for other NTDs (such as lymphatic filariasis) could end up being similarly counter-productive.

\section{Revealing the value of biosocial research}

Although the theoretical, methodological and political challenges of developing biosocial approaches to controlling or eliminating NTDs are considerable, it is vital to find ways to overcome them. All the articles published in this special issue illustrate the point. They either reflect critically on research that does not combine insights from the biological and social sciences - and demonstrate how over-reliance on biological or social approaches limits our understanding of transmission, control or prevention - or they highlight how a biosocial perspective can further our understanding of transmission, control or prevention of NTDs.

The article by Hastings (2016) illustrates how easy it is for NTD control programmes to be de-railed when limited attention is paid to the social, economic and political contexts in which mass treatment is delivered. In the course of long-term ethnographic fieldwork in Morogoro, Tanzania, riots broke out while teachers were handing out medicines to school children for the prevention and treatment of S. haematobium. These riots occurred in other parts of Tanzania too and the mass drug administration programme was halted. By analysing the rumours and violence surrounding the programme, Hastings' article demonstrates what happens when policymakers and practitioners focus on the technical aspects of delivery at the expense of engaging with the specific local contexts.

Stothard et al. (2016) also discuss local understandings and responses to infection with S. haematobium among school children in Tanzania. Focusing on Unguja Island (Zanzibar), their research highlights the limitations of relying solely on health education in schools to alter knowledge and understanding of the life-cycle of schistosomiasis. They go on to suggest that it would be a mistake to assume that children will 'rationally' reduce their contact with contaminated water. Reminding us that only a small number of infected children are needed to sustain the transmission of schistosomiasis, and such transmission can easily occur among pre-school children, their article provides as strong a case as any for social and biological scientists to avoid placing too much emphasis on school-based interventions and to develop broader, more integrated, biosocial approaches to the control of schistosomiasis.

The article by Person et al. (2016) is similarly concerned with controlling schistosomiasis on Unguja Island. Recognizing that community engagement has predominantly been limited to carrying out protocols designed either nationally or internationally, with little - if 
any - consideration for local circumstances, their article presents a new approach whereby local actors are actively involved in the design of interventions seeking to control schistosomiasis. Structural interventions (such as the design of locally appropriate sanitation facilities and laundry washing facilities) are created alongside the development of education materials about schistosomiasis for school children, with a view to modifying risk behaviours and increasing drug coverage. The work is in progress, with the multi-disciplinary approach promising to make a really useful contribution to reducing transmission.

Pearson's biosocial research (Pearson, 2016), which combines the collection of parasitological data with long-term ethnographic fieldwork, examines the low level of schistosomal infection among fisherfolk living along the River Nile in northern Uganda. Her research suggests that while mass drug administration has contributed to a reduction in the prevalence and intensity of $S$. mansoni, this would not have occurred in the absence of wider environmental, social and political changes. Such changes included changing fishing livelihoods, local attitudes to public health interventions, access to water and sanitation facilities, hygiene practices and the use of anti-malarial treatments.

Bardosh et al. (2016) focus on a zoonotic tapeworm, Echinococcus granulosus, in northern Morocco. Infection with this tapeworm can not only lead to losses in livestock production, but also to the development of a serious disease, cystic echinococcosis, in humans. Building on clinical and epidemiological research, Bardosh et al. show how ethnographic fieldwork at Moroccan slaughterhouses can usefully reveal the biosocial pathways facilitating the spread of the tapeworm between dogs, livestock and people. Grounded in an understanding of the political economy of the region, their article rightly calls for a participatory and critically engaged biosocial approach to the control of this neglected zoonotic disease.

Finally, Allen and Parker (2016) draw upon field research in East Africa to provide an assessment of school-based mass drug administration. They show how a key study by Miguel and Kramer (2004) of deworming in Kenya has been much cited as evidence for the effectiveness of large-scale MDA programmes targeting entire populations. However, the findings from this study have been seriously questioned, and this has led to a fierce debate termed the 'Worm Wars' (Evans, 2015). Allen and Parker go on to critically review literature relating to these issues, demonstrating that many claims made about the success of deworming school children in Africa are misleading. Moreover, evidence relating to school-based programmes at various research sites in Uganda and Tanzania shows that actual tablet consumption by children is much lower than has been suggested. The effects differ between the diseases being targeted, but it is clear that the effective delivery of treatments to children requires rethinking in order to sustain any improvement in their well-being.

\section{Conclusion: reversing rhetorics and wrong turnings}

The word 'neglected' in neglected tropical diseases emphasizes social priorities, social relations and social behaviour. It is, therefore, odd that public health interventions for the control of NTDs are persistently framed as technical solutions, which can be rolled out in a uniform way across countries and continents. Regrettably, as time has passed, much of the focus has continued to be on raising funds and scaling-up mass drug administration. Concerns about the biological and social implications of this approach 
have tended to be side-lined, and independent evidence of all kinds has played a worryingly marginal role.

Back in 2011, as part of a collection of articles on the Millennium Development Goals, a critical assessment was made of contemporary approaches to the control NTDs. It was pointed out that optimistic assertions by leading protagonists were open to question. Findings from fieldwork among those at the receiving end of mass drug administration indicated that rhetoric was being emphasized over realities. Without a series effort to assess what is actually happening on the ground, the achievements of the NTD lobby in highlighting the significance of debilitating afflictions could end up being undermined. Indeed, the important work of addressing the health needs of impoverished people might, in practice, be reversed (Allen \& Parker, 2011).

At the time, this was a highly contentious argument, and it prompted some heated exchanges (Reisz, 2013). Five years later, a plethora of studies have subsequently underlined the points made, and indiscriminate mass drug administration programmes are now being subjected to much greater scrutiny (Garner et al., 2015). Nevertheless, large-scale mass drug administration is continuing, and in some ways, positions have hardened. For example, a Cochrane Review on soil-transmitted helminth infections recently concluded that for routine deworming of school children in endemic areas: 'there is quite substantial evidence that programmes do not show benefit in terms of average nutritional status, haemoglobin, cognition, school performance, or death' (Taylor-Robinson et al., 2015). In response, the WHO's Advisory Group on NTDs has continued to claim that mass deworming is: 'the most cost-effective strategy to reach infected children and improve their health and well-being' (WHO, 2015b).

Given how much is at stake, it is unsurprising that some responses to critical perspectives remain defensive. Nevertheless, there is an urgent need for more balanced, less confrontational and better informed discussions. To that end, the articles in this collection try to shift the terms of debate. Rather than rejecting the possibility of controlling NTDs, the authors suggest that developing biosocial approaches potentially offers a more effective way of achieving positive and sustainable outcomes. They also demonstrate how biosocial perspectives add rigour to scholarly analyses. Controlling debilitating and curable ailments that afflict the world's poorest people is a laudable aim, but without the kinds of insights presented here, what have been promoted as short-cuts linked to the availability of free drugs will almost inevitably turn out to be wrong turnings.

\section{Acknowledgments}

A workshop on biosocial approaches to the control of neglected tropical diseases was organized under the auspices of the Biosocial Society in July 2013 at the Royal Anthropological Institute and Brunel University, London. Melissa Parker, Katja Polman and Tim Allen would like to thank Brunel University, the Institute of Tropical Medicine, Antwerp, the London School of Economics and the Biosocial Society for contributing to the costs of the workshop. They are also grateful to the following participants for their thoughtful and often rather lively contributions: Mutamid Amin, Marleen Boelaert, Moses Bockarie, Clare Chandler, Marianne Comparet, Alan Fenwick, John Gyapong, Kate Hampshire, Julie Hastings, Eleanor Hutchinson, Steffi 
Knopp, Warren Lancaster, Edwin Michael, Isaac Neihaus, Giuseppina Ortu, Koen Peeters, Bobbie Person, Angela Pinot de Moira, Maria Rebollo, David Rollinson, Russell Stothard and Johannes Sommerfeld.

\section{References}

Adams, V. (2013) Evidence-based global public health. In Biehl, J. \& Petryna, A. (eds) When People Come First: Critical Studies in Global Health. Princeton University Press, pp. 54-90.

Allen, T. \& Parker, M. (2011) The 'Other Diseases' of the Millennium Development Goals: rhetoric and reality of free drug distribution to cure the poor's parasites. Third World Quarterly 32(1), 91-117.

Allen, T. \& Parker, M. (2012a) Conflicts and compromises: experiences of doing anthropology at the interface of public policy. In Fardon, R., Harris, O., Marchand, T. H. J., Shore, C., Strang, V. \& Wilson, R. A. (eds) Sage Handbook of Social Anthropology. Sage Publishing, London, pp. 184-195.

Allen, T. \& Parker, M. (2012b) Will increased funding for neglected tropical diseases really make poverty history? The Lancet 379(9821), 1097-1098.

Allen, T. \& Parker, M. (2016) Deworming delusions? Mass drug administration in East African schools. Journal of Biosocial Science 48(S1), S116-S147.

Alley, C. \& Sommerfeld, J. (2014) Infectious disease in times of social and ecological changes. Medical Anthropology 33, 85-91.

Allotey, P., Reidpath, D. \& Pokhrel, S. (2010) Social science research in neglected tropical diseases 1: the on-going neglect in neglected tropical diseases. Health Research Policy and Systems $\mathbf{8}, 32$.

Amin, M. \& Abu Bakar, H. (2016) Control of schistosomiasis in the Gezira Irrigation Scheme, Sudan. Journal of Biosocial Science doi:org/10.1017/S0021932016000079.

Bardosh, K. L., El Berbri, I., Ducrotoy, M., Bouslikhane, M., Ouafaa, F. F. \& Welburn, S. C. (2016) Zoonotic encounters at the slaughterhouse: pathways and possibilities for the control of cystic echinococcosis in northern Morocco. Journal of Biosocial Science 48(S1), S92-S115.

Bleakley, H. (2002) Disease and Development: Evidence from Hookworm Eradication in the American South. Report of the Rockefeller Sanitary Commission. URL: http://web.mit.edu/hoyt

Boelaert, M., Meheus, F., Sanchez, A., Singh, S., Vanlerberghe, V., Picado, A. M. et al. (2009) The poorest of the poor: a poverty appraisal of households affected by visceral leishmaniasis in Bihar, India. Tropical Medicine and International Health 14, 639-644.

Cavalli, A., Bamba, S. I., Traore, M. N., Boelaert, M., Coulibaly, Y., Polman, K. et al. (2010) Interactions between global health initiatives and country health systems: the case of a neglected tropical diseases control program in Mali. PLoS Neglected Tropical Diseases 4(8), e798.

Chan, M. (2012) Best Days for Public Health are Ahead of Us. Speech made by the Director General of the WHO on $21^{\text {st }}$ May 2012. URL: http://www.who.int/neglected_diseases/ dgspeech_may2012/en/

Choffnes, E. R. \& Relman, D. A. (2011) The Causes and Impacts of Neglected Tropical and Zoonotic Diseases: Opportunities for Integrated Intervention Strategies. Workshop Summary. National Academy of Sciences, Washington DC.

Coulibaly, Y., Cavalli, A., van Dormael, M., Polman, K. \& Kegels, G. (2008) Programme activities: a major burden for district health systems? Tropical Medicine and International Health 13(12), $1430-1432$.

Dressler, W. W. (2003) What's cultural about biocultural research? ETHOS 33(1), 20-45.

Dufour, D. L. (2006) Biocultural approaches in human biology. American Journal of Human Biology 18(1), 1-9. 
Evans, D. (2015) Worm Wars: The Anthology. World Bank. URL: http://blogs.worldbank.org/ impactevaluations/worm-wars-anthology

Farmer, P., Yong Kim, J., Kleinman, A. \& Basilico, M. (2013) Reimagining Global Health: An Introduction. University of California Press.

Garner, P., Taylor-Robinson, D. \& Sachdev, H. S. (2015) Commentary: replication of influential trial helps international policy. International Journal of Epidemiology 44(5), $1599-1601$.

Geerts, S. \& Gryseels, B. (2000) Drug resistance in human helminths: current situation and lessons from livestock. Clinical Microbiology Reviews 13(2), 207-222.

Goodman, A. H. \& Leatherman, T. L. (eds) (1998) Building a New Biocultural Synthesis. University of Michigan Press.

Gray, D. J., McManua, D. P., Li, Y., Williams, G. M., Bergquist, R. \& Ross, A. G. (2010) Schistosomiasis elimination: lessons from the past guide the future. The Lancet Infectious Diseases 10, 733-736.

Gryseels, B., Polman, K., Clerinx, J. \& Kestens, L. (2006) Human schistosomiasis. The Lancet 368, $1106-1118$.

Hastings, J. (2013) Rumours and riots: local responses to mass drug administration for the treatment of neglected tropical diseases among school-aged children in Morogoro region, Tanzania. PhD dissertation, Department of Anthropology, Brunel University.

Hastings, J. (2016) Rumours, riots and rejection of mass drug administration for the treatment of schistosomiasis in Morogoro, Tanzania. Journal of Biosocial Science 48(S1), S16-S39.

Hotez, P. J., Brindley, P. J., Bethony, J. M., King, C. H., Pearce, E. J. \& Jacobson, J. (2008) Helminth infections: the great neglected tropical diseases. Journal of Clinical Investigation 118(4), 1311-1321.

Hotez, P. J., Fenwick, A., Savioli, L. \& Molyneux, D. H. (2009) Rescuing the bottom billion through control of neglected tropical diseases. The Lancet 373, 1570-1575.

Humphries, D., Nguyen, S., Boakye, D., Wilson, M. \& Cappello, M. (2012) The promise and pitfalls of mass drug administration to control intestinal helminth infections. Current Opinion Infectious Diseases 25(5), 584-589.

Ingold, T. \& Palsson, G. (2013) Prospect. In Ingold, T. \& Palsson, G. (eds) Biosocial Becomings: Integrating Social and Biological Anthropology. Cambridge University Press.

Kabatereine, N. B., Malecela, M., Lado, M., Zaramba, S., Amiel, O. \& Kolaczinski, J. H. (2010) How to (or not to) integrate vertical programmes for the control of major neglected tropical diseases in Sub-Saharan Africa. PLoS Neglected Tropical Diseases 4(6), e755.

Kisoka, W. J., Simonsen, P. E., Malecela, M. N., Tersbol, B. P., Mushi, D. L. \& Meyrowitsch, D. W. (2014) Factors influencing drug uptake during mass drug administration for control of lymphatic filariasis in rural and urban Tanzania. PLoS One 9(10), e109316.

Kisoka, W. J., Tersbol, B. P., Meyrowitsch, D. M., Simonsen, P. E. \& Mushi, D. L. (2016) Community members' perceptions of mass drug administration for control of lymphatic filariasis in rural and urban Tanzania. Journal of Biosocial Science 48(1), 94-112.

Keating, C. (2014) Ken Warren and the Rockefeller Foundation's Great Neglected Diseases Network, 1978-1988: the transformation of tropical and global medicine. Molecular Medicine 20 (Supplement 1), S24-S30.

Kleinman, A., Das, V. \& Lock, M. (1997) Social Suffering. University of California Press, Berkeley, CA.

Kleinman, A. M., Bloom, B. R., Saich, A., Mason, K. A. \& Aulino, K. (2008) Asian flus in ethnographic and political context: a biosocial approach. Anthropology and Medicine 15(1), 1-5.

Leatherman, T. L. \& Goodman, A. G. (2011) Critical biocultural approaches in medical anthropology. In Singer, M. \& Erickson, P. I., (eds) A Companion to Medical Anthropology. Wiley Blackwell Companions to Anthropology, Blackwell Publishing, Oxford, pp. 29-48. 
Lock, M. (1993) Encounters with Aging: Mythologies of Menopause in Japan and North America. University of California Press, Berkeley, CA.

Lock, M. (2001) The tempering of medical anthropology: troubling natural categories. Medical Anthropology Quarterly 15, 478-492.

Mahmoud, A. \& Zerhouni, E. (2009) Neglected tropical diseases: moving beyond mass drug treatment to understanding the science. Health Affairs 28(6), 1726-1733.

Marchal, B., Van Dormael, M., Pirard, M., Cavalli, A., Kegels, G. \& Polman, K. (2011) Neglected tropical disease (NTD) control in health systems: the interface between programmes and general health services. Acta Tropica 1205, S177-S185.

Meheus, F., Rijal, S., Lutumba, P., Hendrickx, D. \& Boelaert, M. (2012) NTD control and health system strengthening. The Lancet 379, 2149-2150.

Miguel, E. \& Kremer, M. (2004) Worms: identifying impacts on education and health in the presence of treatment externalities. Econometrica 72(1), 159-217.

Molyneux, D. H. (2012) The 'Neglected Tropical Diseases': now a brand identity; responsibilities, context and promise. Parasites \& Vectors 5, 23.

Molyneux, D. H., Hotez, P. J. \& Fenwick, A. (2005) Rapid-impact interventions: how a policy of integrated control for Africa's neglected tropical diseases could benefit the poor. PLoS Medicine 2(11), e.336.

Mosse, D. (2004) Is good policy unimplementable? Reflections on the ethnography of aid policy and practice. Development and Change 35(4), 639-671.

Mosse, D. (2005) Cultivating Development: An Ethnography of Aid Policy and Practice. Pluto Press, London.

Mosse, D. (ed.) (2013) Adventures in Aidland: The Anthropology of Professionals in International Development. Berghahn Press, Oxford.

Muhumuza, S., Olsen, A., Katahoire, A. \& Nuwaha, F. (2013) Uptake of preventive treatment for intestinal schistosomiasis among school children in Jinja District, Uganda: a cross sectional study. PLoS One 8(5), e63438.

Muhumuza, S., Olsen, A., Katahoire, A. \& Nuwaha, F. (2015) Understanding low uptake of mass treatment for intestinal schistosomiasis among school children: a qualitative study in Jinja district, Uganda. Journal of Biosocial Science 47(4), 505-520.

Nikolay, B., Mwandawiro, C. S., Kihara, J. H., Okoyo, C., Cano, J., Mwanje, M. T. et al. (2015) Understanding heterogeneity in the impact of national neglected tropical disease control programmes: evidence from school-based deworming in Kenya. PLoS Neglected Tropical Diseases 9(9), e0004108.

Nordrum, A. (2015) How three scientists 'marketed' neglected tropical diseases and raised more than $\$ 1$ billion. International Business Times. URL: http://www.ibtimes.com/how-threescientists-marketed-neglected-tropical-diseases-raised-more-1-billion-1921008

Parker, M. \& Allen, T. (2011) 'Does mass drug administration for the integrated treatment of neglected tropical diseases really work? Assessing evidence for the control of schistosomiasis and soil-transmitted helminths in Uganda. Health Research Policy and Systems 9, 3.

Parker, M. \& Allen, T. (2013) Will mass drug administration eliminate lymphatic filariasis? Evidence from northern coastal Tanzania. Journal of Biosocial Science 45, 517-545.

Parker, M. \& Allen, T. (2014) De-politicizing parasites: reflections on attempts to control the control of neglected tropical diseases. Medical Anthropology 33(3), 223-239.

Parker, M., Allen, T. \& Hastings, J. (2008) Resisting control of neglected tropical diseases: dilemmas in the mass treatment of schistosomiasis and soil-transmitted helminths in north-west Uganda. Journal of Biosocial Science 40, 161-181.

Parker, M., Allen, T., Pearson, G., Peach, N., Flynn, R. \& Rees, N. (2012) Border parasites: schistosomiasis control among Uganda's fisherfolk. Journal of Eastern African Studies 6(1), $97-122$. 
Parker, M. \& Harper, I. (2006) The anthropology of public health: an introduction. Journal of Biosocial Science 38(1), 1-5.

Pearson, G. (2016) Low prevalence of intestinal schistosomiasis among fisherfolk living along the River Nile in northwestern Uganda: a biosocial investigation. Journal of Biosocial Science 48(S1), S74-S91.

Person, B. S., Knopp, S., Ali, S. M., Kadir, F. M. A., Khamis, A. N., Ali, J. N. et al. (2016) Community co-designed schistosomisias interventions for school-aged children in Zanzibar. Journal of Biosocial Science 48(S1), S56-S73.

Policy Cures. (2012) Investing in R\&D for Neglected Diseases: A Public Pull-Out Puts Lives at Risk. Press Release. URL: http://www.policycures.org/downloads/G-FINDER\%202013\% 20press\%20release.pdf (accessed 23rd June 2014).

Ranganath, B. G. (2010) Coverage survey for assessing mass drug administration against lymphatic filariasis in Gulbarga district, Karnataka, India. Journal of Vector Borne Diseases 47, $61-64$.

Regnier, M. (2012) Neglected Tropical Diseases: The Campaign Trail. URL: http://blog.wellcome. ac.uk/2012/01/10/neglected-tropical-diseases-the-campaign-trail/ (accessed $10^{\text {th }}$ January 2012).

Reisz, M. (2013) Unwanted side-effects. Times Higher Education, 30 ${ }^{\text {th }}$ May 2013.

Roy, R. N., Sarkar, A. P., Misra, R., Chakroborty, A., Mondal, T. K. \& Bag, K. (2013) Coverage and awareness of and compliance with mass drug administration for elimination of lymphatic filariasis in Burdwan District, West Bengal, India. Journal of Health, Population and Nutrition 31(2), 171-177.

Saeed, K., El Wali, M., Dessein, J., Adeel, A., Magzoub, M., El Samani, K. E. et al. (2006) Schistosoma mansoni associated morbidity in Gezira: determined by clinical and ultrasound examination. Sudanese Journal of Public Health 1(1), 27-30.

Samsky, A. (2012) Scientific sovereignty: how international drug donation programs reshape health, disease, and the state. Cultural Anthropology 27(2), 310-332.

Savioli, L., Montresor, A. \& Gabrielli, A. F. (2011) Neglected tropical diseases: the development of a brand with no copyright. A shift from a disease centred approach to a tool-centred strategic approach. In Choffnes, E. R. \& Relman, D. A. (eds) The Causes and Impacts of Neglected Tropical and Zoonotic Diseases: Opportunities for Integrated Intervention Strategies. Workshop Summary. National Academy of Sciences, Institute of Medicine, Washington DC. pp. 481-489.

Singer, M. (2015) Anthropology of Infectious Disease. Left Coast Press, CA.

Singer, M. \& Clare, S. (2003) Syndemics and public health: reconceptualizing disease in bio-social context. Medical Anthropology Quarterly 17(4), 423-441.

Simonsen, P. E., Pederson, E. M., Rwegoshora, R. T., Malecela, M. N., Derua, Y. A. \& Magesa, S. (2010) Lymphatic filariasis control in Tanzania: effect of repeated mass drug administration with ivermectin and albendazole on infection and transmission. PLoS Neglected Tropical Diseases 4(6), e695.

Sommerfeld, J. (2003) Plagues and peoples revisited. European Molecular Biology Organisation Reports 4 (Supplement 1), S32-S34.

Stothard, J. R., Khamis, A. N., Khamis, I. S., Neo, C. H. E., Wei, I. \& Rollinson, D. (2016) Health education and the control of urogenital schistosomiasis: assessing the impact of the Juma Na Kichocho comic-strip medical booklet in Zanzibar. Journal of Biosocial Science 48(S1), S40-S55.

Taylor-Robinson, D. C., Maayan, N., Soares-Weiser, K., Donegan, S. \& Garner, P. (2015) Deworming drugs for soil-transmitted intestinal worms in children: effects on nutritional indicators, haemoglobin, and school performance. Cochrane Database Systematic Review, $23^{\text {rd }}$ July 7, CD000371. doi: 10.1002/14651858.CD000371.pub6.

Tuhebwe, D., Bagonza, J., Kiracho, E. E., Yeka, A., Elliott, A. M. \& Nuwaha, F. (2015) Uptake of mass drug administration programme for schistosomiasis control in Koome Islands, Central Uganda. PLoS One 10(4), e0123673. 
Waghorn, T. S., Leathwick, D. M., Rhodes, A. P., Lawrence, K. E., Jackson, R., Pomroy, W. E. et al. (2006) Prevalence of anthelmintic resistance on sheep farms in New Zealand. New Zealand Veterinary Journal 54(6), 271-277.

World Health Organization (2015a) Investing to Overcome the Global Impact of Neglected Tropical Diseases: Third WHO Report on Neglected Diseases 2015. WHO, Geneva.

World Health Organization (2015b) Advisory Body Upholds Continued Deworming of Children Against Soil-Transmitted Helminthiases. URL: http://www.who.int/neglected_diseases/news/ update-deworming-children/en/

World Health Organization (2013) Sustaining the Drive to Overcome the Global Impact of Neglected Tropical Diseases. Second WHO Report on Neglected Tropical Diseases. WHO, Geneva.

World Health Organization (2010) World Health Organization: Working to Overcome the Global Impact of Neglected Tropical Diseases. First WHO Report on Neglected Tropical Diseases. WHO, Geneva.

Yamey, G. (2009) The unsung hero of neglected tropical diseases: interview with Narcis Kabatereine. PLoS Neglected Tropical Diseases 3(12), e546. 